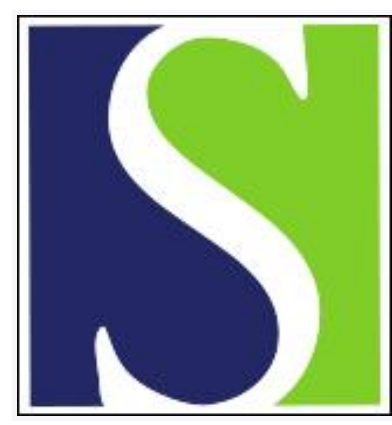

Scand J Work Environ Health 2006;32(1):22-31

https://doi.org/10.5271/sjweh.973

Issue date: 31 Feb 2006

\title{
Update of a meta-analysis on lung cancer and welding
}

by Ambroise D, Wild P, Moulin J-J

Affiliation: Département Epidémiologie en Entreprises - INRS, BP 27, 54501 Vandoeuvre Les Nancy, France. denis.ambroise@inrs.fr

The following articles refer to this text: 2007;33(5):379-386;

2008;34(6):444-450

Key terms: epidemiologic study; heterogeneity; lung cancer; meta-analysis; publication bias; stainless steel; welding

This article in PubMed: www.ncbi.nlm.nih.gov/pubmed/16539169 


\title{
Update of a meta-analysis on lung cancer and welding
}

\author{
by Denis Ambroise, MD, ${ }^{1}$ Pascal Wild, PhD, ${ }^{1}$ Jean-Jacques Moulin, MD ${ }^{1}$
}

\begin{abstract}
Ambroise D, Wild P, Moulin J-J. Update of a meta-analysis on lung cancer and welding. Scand J Work Environ Health 2006;32(1):22-31.
\end{abstract}

Objectives This study is an update, over the period 1954-2004, of a previous meta-analysis completed in 1994. It was aimed at assessing lung cancer risk among welders, while addressing heterogeneity, publication bias, and confounding issues.

Methods Combined relative risks (CRR) and their variances were calculated using fixed and random effects models. Heterogeneity was tested using the Q statistic. The publication bias was estimated using funnel plots, and Egger's regression and partially controlled by excluding studies with positive reporting bias.

Results The literature provided 60 studies eligible for the meta-analysis. No heterogeneity was observed. The fixed effect CRR for all of the welders and all of the studies was 1.26 (95\% CI 1.20-1.32) after partial control of publication bias. No difference was observed according to welding activities. Smoking did not appear to be a marked confounder in the relationship between lung cancer and welding, but the effect of asbestos could not be assessed.

Conclusions The meta-analysis showed a $26 \%$ excess of lung cancer for welders without any difference according to welding activities.

Key terms epidemiologic study; heterogeneity; publication bias; stainless steel.

Following the publication of the IARC Monograph on the carcinogenic effects of exposure to chromium, nickel, and welding (1), we published a meta-analysis of epidemiologic studies on lung cancer among welders (2). The study covered the period 1954-1994, was aimed at assessing the relationship between lung cancer and welding activities, in particular welding stainless steel, which generates exposure to chromium and nickel compounds, and welding in shipyards, which is likely to be associated with asbestos exposure (1).

This meta-analysis, which showed a $30 \%$ to $40 \%$ increase in the relative risk of lung cancer among welders as compared with rates in the general population, found no excess lung cancer risk among shipyard and stainless steel welders when compared with mild steel welders (2). Another outcome of the meta-analysis was the difficulty to assess the relative importance of smoking and concomitant exposure to asbestos as possible confounding factors (2).

Our present report is an update of the previous metaanalysis throughout the period 1954-2004. It takes a closer look at the issues of study heterogeneity and publication biases in light of recent methodological developments (3-6). Another aim was to investigate further the comparison of shipyard, stainless steel, and mild steel welders and improve the assessment of confounding due to smoking.

\section{Study population and methods}

\section{Selection of studies}

A search was conducted of the literature using the Medline, Toxline, and NIOSHTIC2 databases and the keywords "welding \& cancer", "welding \& mortality", "welding \& respiratory tract neoplasm", "welder \& cancer", "lung \& cancer \& occupational \& epidemiology", "respiratory tract neoplasm \& occupational \& case control study".

The abstracts of the several hundred papers thus selected were screened for their potential interest. The selected papers were read extensively and complemented by the references quoted therein. Finally a total of 80 potentially interesting studies were thus included.

1 Département Epidémiologie en Entreprises - INRS (Department of Industry-based Epidemilogy—French National Institute for Research and Safety), Vandoeuvre Les Nancy, France.

Correspondence to : Dr P Wild, Département Epidémiologie en Entreprises - INRS, BP 27, 54501 Vandoeuvre Les Nancy, France. [E-mail: pascal.wild@inrs.fr] 
On the basis of the detailed assessment, 20 papers were excluded according to the following systematic exclusion criteria: (i) if later updates were available (720), (ii) if it was a mortality statistic (21) and a cancer morbidity study was available (22), (iii) the papers republished data $(23,24)$ that were already available elsewhere $(25,26)$, (iv) the metal welded was atypical (lead) or the welders were resistence welders $(27,28)$, and (v) the description of the welder population was insufficient (29).

The largest industry-based cohort study was the multicentric IARC study, which included large historical subcohorts from nine European countries $(30,31)$. Due to the fact that five of these subcohorts (ie, Finland, France, Germany, Norway, Sweden) had been separately published or updated $(26,32-35)$, the IARC study itself was excluded from the database of the metaanalysis. However, in order to avoid losing the information provided by the four other unpublished subcohorts (ie, Denmark, England, Italy, Scotland), we extracted the relevant data on these subcohorts from the IARC study report (30) and included them in the database.

\section{Data collection}

The following three subcategories of welders were considered: shipyard, mild steel, and stainless steel welders. When no information as to the welding type was available, a generic nonspecific welding category was created.

For each study, data on the observed number of lung cancer cases, relative risk and their $95 \%$ confidence intervals $(95 \% \mathrm{CI})$ were abstracted and selected by consensus of the authors, along with data on potential sources of heterogeneity (study design, country and year of publication, welding activity). The relative risks obtained from case-control studies (population-based and cohort-nested case-control studies) were either mortality odds ratios (MOR) or incidence odds ratios (IOR). Those published in cohort mortality studies were standardized mortality ratios (SMR) or proportional mortality ratios (PMR), and they were standardized incidence ratios (SIR) in cancer incidence studies. For some cohort studies that provided internal relative risks, we denoted incidence rate ratios (IRR) or mortality rate ratios (MRR) as relevant (35-37). When a study provided more than one effect measure, the authors extracted what they considered the " best estimate " [ie, odds ratios adjusted for smoking and other confounders instead of crude odds ratios in case-control studies, and internal relative risks (IRR and MRR) (internal references) or odds ratios (nested case-control study) instead of SMR or SIR values in industrial cohort-based studies.
We abstracted all published relative risks referring to dose-response relationships according to the following surrogates: duration of exposure or other quantitative parameters. However, dose-response relationships were not addressed in the meta-analysis since, depending on the study, relative risks for graded welding exposure were either lacking or given using different surrogates.

In an attempt to take into account publication bias, we considered the fact that, depending on the study design, some results may have been published because they revealed a positive association between lung cancer and welding. This bias is likely to occur in population-based studies, in particular in cases of record linkage, which provide numerous relative risks calculated for many effects in many occupational groups. In most of these studies, which were set up to generate hypotheses, the authors reported only positive associations. For our present study, code B (ie, biased) was assigned to a study whenever the authors indicated that only "statistically significant relative risks" or only relative risks "higher than a given value" were reported. Consequently, the other studies were considered as a group without positive reporting bias. Exclusion of the studies with a mentioned positive reporting bias could partially control for publication bias.

All available smoking information was abstracted from the papers. Some of the studies, mainly population based case-control studies and nested case-control studies, provided smoking-adjusted odds ratios. Conversely, due to a lack of data, most of the cohort studies did not take smoking into account. However, some cohort studies used Axelson's method (38) to assess the confounding risk ratio (39) due to smoking. Using this information, we calculated an estimate of the smoking adjusted SMR values or SIR values by dividing the reported SMR values or SIR values by the confounding risk ratio derived using Axelson's method.

\section{Statistical analysis}

Combined relative risks (CRR) were calculated using fixed and random effects models. The variance and the precision (defined as the inverted variance $\mathrm{w}_{i}$ ) of given study $i$ were calculated on the assumption that the logtransformed relative risks followed a Gaussian distribution. The logarithms of the CRR values were computed as an average of the log-transformed relative risks, weighted by their precision for the fixed effect and their random-effect weights $\mathrm{w}_{i}$ for the random effect estimate. The precision of the CRR values is the sum of the respective weights (3-4). 
To test heterogeneity, we used the standard $Q$ statistic (3-4). The potential sources of heterogeneity that were addressed were study design and welding categories (as in our previous meta-analysis), study countries, publication years, types of relative risks, mortality or morbidity endpoints, and analytical approaches to control for smoking.

To assess the effect of publication bias, we constructed funnel plots which are a scatterplot of the $\mathrm{LnRR}_{i}$ versus their precision $\mathrm{w}_{i}(6)$. Publication bias was revealed by asymmetry of the funnel plot (6). To measure this funnel plot asymmetry, we used a linear regression approach (the so-called Egger regression) by regressing the standardized coefficients (LnRR/se(LnRR) against $1 / \operatorname{se}(\operatorname{LnRR})$ (6). In the absence of publication bias, the regression line runs through the origin. The intercept of the regression line provides a measure of the funnel plot asymmetry, the larger its deviation from zero the more pronounced the asymmetry (6).
All of the analyses were repeated with restriction on the set of studies without positive reporting bias.

\section{Results}

\section{Description of the studies}

The complete listing of the included studies $(22,25-26$, $30-37,40-88$ ) is given in table 1 . These studies examined populations in 14 different countries, most of the studies having been conducted in the United States (26 studies) and Europe (26 studies), of which 12 were from Nordic countries. The numbers of studies according to years of publication were 21 studies between 19541985, 17 studies between 1986-1993, and 22 studies after 1993. Altogether $24(40 \%)$ new studies had not been included in the former meta-analysis.

Table 1. Relative risks and $95 \%$ confidence intervals $(95 \% \mathrm{CI})$ according to study design and welding category. [All = all welding categories, SY = shipyard welding, MS = mild steel welding, SS = stainless steel welding, B = only positive associations were reported, $\mathrm{Y}=$ not included in our previous meta-analysis (2)]

\begin{tabular}{|c|c|c|c|c|c|c|c|}
\hline Study & Country & Welding category & Observed number ${ }^{a}$ & Relative risk $^{b}$ & $95 \% \mathrm{Cl}$ & Bias & New studyc \\
\hline \multicolumn{8}{|l|}{ Morbidity and mortality statistics } \\
\hline Enterline et al, 1963 (40) & United States & All & 34 & SMR 0.92 & $0.64-1.29$ & & \\
\hline Menck et al, 1976 (41) & United States & All & 48 & SMR 1.37 & $1.01-1.82$ & B & \\
\hline Decoufle et al, 1978 (42) & United States & All & 11 & MOR 0.85 & $0.50-1.50$ & & \\
\hline Population census,1978 (43) & United Kingdom & All & 246 & SMR 1.51 & $1.33-1.71$ & B & \\
\hline Gottlieb et al, 1980 (44) & United States & All & 8 & MOR 3.50 & $0.73-16.70$ & B & \\
\hline Petersen et al, 1980 (45) & United States & All & 37 & PMR 0.99 & $0.61-1.40$ & & \\
\hline Milne et al, 1983 (46) & United States & All & 5 & MOR 1.31 & $0.43-3.59$ & & \\
\hline Gallagher et al, 1983 (47) & Canada & All & 74 & PMR 1.45 & $1.15-1.83$ & B & \\
\hline Sjögren et al, 1986 (22) & Sweden & All & 193 & SIR 1.30 & $1.12-1.50$ & & \\
\hline Firth et al, 1993 (48) & New Zealand & All & 200 & MOR 1.40 & $1.21-1.61$ & B & Y \\
\hline Milham et al, 1997 (49) & United States & All & 267 & PMR 1.31 & $1.16-1.50$ & Y & \\
\hline Burnett et al, 1997 (50) & United States & All & 1097 & PMR 1.24 & $1.18-1.30$ & B & Y \\
\hline Andersen et al, 1999 (51) & Nordic countries & All & 650 & SIR 1.23 & $1.14-1.33$ & & Y \\
\hline \multicolumn{8}{|c|}{ Population based case-control studies } \\
\hline Breslow et al, 1954 (52) & United States & All & 14 & IOR 7.18 & $1.62-31.74$ & B & \\
\hline Blot et al, 1978 (53) & United States & SY & 11 & IOR 0.70 & $0.32-1.41$ & & \\
\hline Blot et al, 1980 (54) & United States & SY & 11 & MOR 0.9 & $0.4-2.3$ & & \\
\hline \multirow[t]{3}{*}{ Gérin et al, 1984 (55) } & Canada & MS & 2 & IOR 1.2 & $0.1-9.4$ & B & \\
\hline & & All & 12 & IOR 2.4 & $1.0-5.4$ & B & \\
\hline & & SS & 10 & IOR 3.3 & $1.2-9.2$ & B & \\
\hline Buiatti et al, 1985 (56) & Italy & All & 7 & IOR 2.8 & $0.9-8.5$ & B & \\
\hline \multirow[t]{2}{*}{ Kjuus et al, 1986 (57 } & Norway & All & 28 & IOR 1.9 & $0.9-3.7$ & B & \\
\hline & Norway & SS & 16 & IOR 3.3 & $1.2-9.3$ & B & \\
\hline \multirow[t]{2}{*}{ Schoenberg et al, 1987 (58) } & United States & All & 38 & IOR 1.19 & $0.75-1.88$ & & \\
\hline & United States & SY & 33 & IOR 2.5 & $1.1-5.5$ & & \\
\hline \multirow[t]{2}{*}{ Lerchen et al, 1987 (59) } & United States & SY & 6 & IOR 2.2 & $0.5-9.1$ & B & \\
\hline & United States & All & 19 & IOR 3.2 & $1.4-7.4$ & B & \\
\hline Benhamou et al, 1988 (60) & France & All & 18 & IOR 1.42 & $0.79-2.88$ & B & \\
\hline Ronco et al, 1988 (61) & Italy & All & 6 & MOR 2.93 & $0.87-9.82$ & & \\
\hline Zahm et al, 1989 (62) & United States & All & 29 & IOR 1.2 & $0.7-2.1$ & & \\
\hline \multirow[t]{3}{*}{ Hull et al, 1989 (63) } & United States & SS & 34 & IOR 0.9 & $0.5-1.8$ & & \\
\hline & United States & MS & 56 & IOR 1.6 & $0.8-3.1$ & & \\
\hline & United States & SY & 37 & IOR 1.7 & $0.9-3.1$ & & \\
\hline Morabia et al, 1992 (64) & United States & All & 18 & IOR 1.5 & $0.8-2.7$ & B & \\
\hline Finkelstein et al, 1995 (65) & Canada & All & 18 & MOR 1.07 & $0.57-1.91$ & $\mathrm{Y}$ & \\
\hline de Stefani et al, 1996 (66) & Uruguay & All & 18 & IOR 1.4 & $0.7-2.8$ & Y & \\
\hline
\end{tabular}


Table 1. Continued.

\begin{tabular}{|c|c|c|c|c|c|c|c|}
\hline Study & Country & Welding category & Observed number ${ }^{\mathrm{a}}$ & Relative risk ${ }^{\mathrm{b}}$ & $95 \% \mathrm{Cl}$ & Bias & New studyc \\
\hline Van Loon et al, 1997 (67) & Netherlands & All & 63 & IOR 0.86 & $0.46-1.58$ & Y & \\
\hline Jöckel et al, 1998 (25) & Germany & All & 233 & IOR 1.25 & $0.94-1.65$ & $\mathrm{Y}$ & \\
\hline Pezzoto et al, 1999 (68) & Argentina & All & 11 & IOR 1.1 & $0.4-3.1$ & Y & \\
\hline Gustavson et al, 2000 (69) & Sweden & All & 99 & IOR 1.44 & $1.08-1.92$ & Y & \\
\hline Matos et al, $2000(70)$ & Argentina & All & 5 & IOR 1.6 & $0.4-6.2$ & & Y \\
\hline \multicolumn{8}{|l|}{ Industrial cohort studies } \\
\hline Dunn et al 1968 (71) & United States & All & 49 & SMR 1.05 & $0.78-1.39$ & & \\
\hline Ott et al, 1976 (72) & United States & All & 2 & SMR 1.00 & $0.11-3.61$ & $\mathrm{Y}$ & \\
\hline Redmond et al, 1981 (73) & United States & All & 14 & SMR 1.51 & $0.82-2.53$ & & \\
\hline Beaumont et al, 1981 (36) & United States & SY & 50 & MRR 1.28 & $0.89-1.84$ & & \\
\hline \multirow[t]{3}{*}{ Polednak et al, 1981 (74) } & United States & SS & 7 & SMR 1.24 & $0.5-2.55$ & & \\
\hline & United States & All & 17 & SMR 1.50 & $0.87-2.39$ & & \\
\hline & United States & MS & 10 & SMR 1.75 & $0.84-3.22$ & & \\
\hline McMillan et al, 1983 (75) & United Kingdom & SY & 5 & PMR 1.04 & $0.34-2.43$ & & \\
\hline Fletcher et al, 1984 (76) & United Kingdom & All & 8 & SMR 1.46 & $0.62-2.88$ & & \\
\hline Newhouse et al, 1985 (77) & United Kingdom & SY & 26 & SMR 1.13 & $0.80-1.57$ & & \\
\hline Rinsky et al, 1988 (78) & United States & SY & 41 & MOR 1.13 & $0.76-1.68$ & & \\
\hline \multirow[t]{2}{*}{ Tola et al, 1988 (32) } & Finland & SY & 27 & SIR 1.15 & $0.76-1.67$ & & \\
\hline & Finland & MS & 14 & SIR 1.35 & $0.74-2.26$ & & \\
\hline Merlo et al, 1989 (79) & Italy & SY & 16 & SMR 1.67 & $0.95-2.71$ & & \\
\hline \multirow[t]{8}{*}{ Simonato et al, 1991 (30-31) } & Italy & SS & 1 & SMR 0.76 & $0.02-4.21$ & & \\
\hline & England & SS & 7 & SMR 1.01 & $0.40-2.08$ & & \\
\hline & Italy & All & 3 & SMR 1.11 & $0.23-3.26$ & & \\
\hline & Scotland & SS & 7 & SMR 1.40 & $0.56-2.88$ & & \\
\hline & Italy & SY & 2 & SMR 1.46 & $0.18-5.28$ & & \\
\hline & Denmark & MS & 7 & SMR 1.50 & $0.60-3.09$ & & \\
\hline & Denmark & All & 30 & SMR 1.57 & $1.06-2.23$ & & \\
\hline & Denmark & SS & 23 & SMR 1.62 & $1.03-2.44$ & & \\
\hline \multirow[t]{4}{*}{ Moulin et al, 1993 (33) } & France & SY & 3 & SMR 0.91 & $0.19-2.67$ & & \\
\hline & France & SS & 3 & SMR 0.92 & $0.19-2.69$ & & \\
\hline & France & All & 19 & SMR 1.24 & $0.75-1.94$ & & \\
\hline & France & MS & 9 & SMR 1.59 & $0.73-3.02$ & & \\
\hline Danielsen et al, 1993 (80) & Norway & SY & 9 & SIR 2.50 & $1.14-4.75$ & & \\
\hline Park et al, 19994 (81) & United States & All & 7 & MOR 2.73 & $1.20-6.30$ & Y & \\
\hline \multirow[t]{3}{*}{ Lauritsen et al, 1996 (26) } & Norway & MS & 26 & MOR 1.3 & $0.8-2.1$ & Y & \\
\hline & Norway & All & 46 & MOR 1.5 & $1.0-2.4$ & $\mathrm{Y}$ & \\
\hline & Norway & SS & 20 & MOR 1.5 & $0.8-2.6$ & Y & \\
\hline \multirow[t]{2}{*}{ Danielsen et al, 1996 (82) } & Norway & SS & 6 & SIR 1.03 & $0.38-2.26$ & Y & \\
\hline & Norway & All & 50 & SIR 1.33 & $0.99-1.76$ & Y & \\
\hline Austin et al, 1997 (83) & United States & All & 7 & MOR 0.76 & $0.28-2.10$ & Y & \\
\hline Stern et al, 1997 (84) & United States & All & 92 & PMR 1.23 & $0.99-1.51$ & Y & \\
\hline \multirow[t]{2}{*}{ Milatou-Smith et al, 1997 (34) } & Sweden & MS & 2 & SMR 0.41 & $0.05-1.48$ & Y & \\
\hline & Sweden & SS & 6 & SMR 1.64 & $0.60-3.58$ & Y & \\
\hline Danielsen et al, 1998 (85) & Norway & SY & 10 & SIR 1.55 & $0.74-2.84$ & Y & \\
\hline de Silva et al, 1999 (86) & United States & All & 4 & SMR 1.10 & $0.30-2.81$ & $\mathrm{Y}$ & \\
\hline Becker et al, 1999 (35) & Germany & SS & 28 & MRR 1.30 & $0.80-2.12$ & Y & \\
\hline Danielsen et al, 2000 (87) & Norway & SY & 9 & SIR 1.27 & $0.58-2.42$ & Y & \\
\hline Puntoni et al, 2001 (88) & Italy & SY & 33 & SMR 1.61 & $1.11-2.26$ & Y & \\
\hline Steenland et al, 2002 (37) & United States & MS & 108 & MRR 1.22 & $0.93-1.59$ & & Y \\
\hline
\end{tabular}

a Observed numbers of lung cancer cases (case-control studies), lung cancer deaths (mortality studies), lung cancer diagnoses (cancer incidence studies).

${ }^{b}$ Relative risks and $95 \% \mathrm{Cl}$ abstracted from the IARC report (30).

There were 13 population surveys, 20 case-control studies, and 27 industry-based cohorts, of which 4 included a nested case-control study. Some studies that provided results for more than one welding category may have contributed to several welding categories. This possibility led to 83 relative risks extracted from the published papers. The distribution of the relative risks was 28 SMR values, 6 PMR values, 9 SIR values, 24 IOR values, 13 MOR values, and 3 MRR values.
Most of the relative risks ( 44 of $83=53 \%$ ) provided information on nonspecific welding categories, smaller numbers (17, 9, and 13 relative risks) concerned shipyard, mild steel, and stainless steel welding, respectively. For five studies $(26,30,33,55,74)$, relative risks concerning the category nonspecific welders were excluded from the CRR calculation whenever all of the subgroups of the same populations (ie, shipyard, mild steel, or stainless steel welders) were already included in the calculation. 
A positive reporting publication bias (ie, studies coded B) was identified for $6(46 \%)$ of 13 relative risks in the population surveys and for $11(41 \%)$ of the 27 relative risks in population-based case-control studies, whereas no such bias was detected in the cohort studies (0 of 43 studies) (table 1 ). With regard to smoking, the high proportion of adjusted relative risks provided by the case-control studies [19 (70\%) of 27] contrasted with the low proportions observed in the population surveys [2 (15\%) of 13) and the cohort studies [6 (14\%) of 43].

When the observed numbers, relative risks, and $95 \%$ confidence intervals were considered according to study designs and welding category, it appeared that the greatest numbers of observed cases were obtained in the population surveys [6 (46\%) of 13 with 200 or more lung cancer cases among the welders]. This result contrasted with the study size of the case-control and cohort studies, in which most of the observed numbers of cases were below 100. Another contrast is that the population surveys provided results on the nonspecific welding category only, whereas several case-control or cohort studies could assess lung cancer risks according to shipyard, mild steel, or stainless steel welding separately.

\section{Meta-analysis}

Figure 1 and table 2 show the effect of the selection bias. In the total database a significant funnel plot asymmetry, as computed from the Egger regression, was detected. When studies with a positive reporting bias were excluded, the overall CRR decreased from $1.28(95 \%$ CI $1.24-1.32)$ to $1.26(95 \%$ CI $1.21-1.32)$. In addition, the studies with a positive reporting bias were

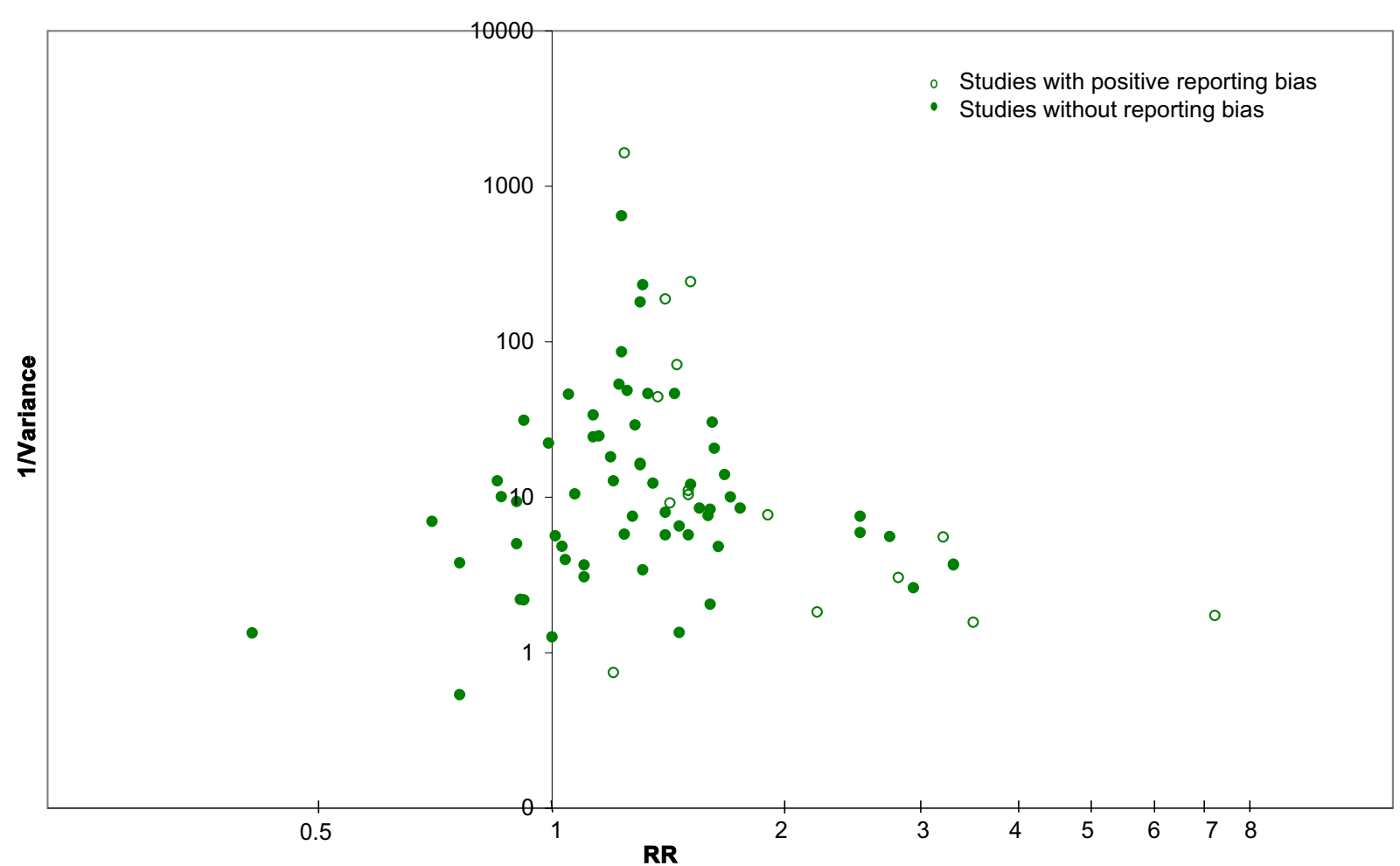

Figure 1. Funnel plot of the precision versus relative risk $(\mathrm{RR})$ on a logarithmic scale [Y axis: precision $=(\text { variance })^{-1} ; \mathrm{X}$ axis: $\mathrm{RR}(\mathrm{CRR}=1.26)$ ].

Table 2. Meta-analysis considering publication bias. ${ }^{a}(\mathrm{CRR}=$ combined relative risks, $95 \% \mathrm{Cl}=95 \%$ confidence interval)

\begin{tabular}{|c|c|c|c|c|c|c|c|c|c|}
\hline \multirow[t]{2}{*}{ Type of study } & \multirow{2}{*}{$\begin{array}{l}\text { Number } \\
\text { of } \\
\text { relative risks }\end{array}$} & \multicolumn{2}{|c|}{ Fixed effects } & \multicolumn{2}{|c|}{ Random effects } & \multirow[t]{2}{*}{$Q$ statistic } & \multirow[t]{2}{*}{ P-value } & \multicolumn{2}{|c|}{ Egger regression } \\
\hline & & CRR & $95 \% \mathrm{Cl}$ & CRR & $95 \% \mathrm{Cl}$ & & & Intercept & $95 \% \mathrm{Cl}$ \\
\hline Biased a & 16 & 1.30 & $1.25-1.36$ & 1.50 & $1.32-1.70$ & 32.3 & 0.006 & 1.40 & $0.83-1.972$ \\
\hline Unbiased ${ }^{b}$ & 61 & 1.26 & $1.20-1.32$ & 1.26 & $1.20-1.32$ & 41.3 & 0.97 & 0.06 & $-0.25-0.43$ \\
\hline All studies & 77 & 1.28 & $1.24-1.32$ & 1.28 & $1.24-1.32$ & 75.0 & 0.51 & 0.30 & $0.02-0.62$ \\
\hline
\end{tabular}

a Papers indicating that only positive associations are reported.

" Papers without any indication of selective reporting (ie, "unbiased results"). 
heterogeneous, and, when they were excluded, the asymmetry in the funnel plot, as assessed by the Egger regression, virtually disappeared. All further description is therefore restricted to the studies without this positive reporting bias.

Table 3 presents the results according to study design and endpoints, types of relative risks, and welding categories. The meta-analysis using fixed and random effect models led to similar and significantly elevated CRR values for the case-control and cohort studies, 1.27 (95\% CI 1.11-1.46) and 1.29 (95\% CI $1.19-1.40$ ), respectively (table 3 ). The CRR was slightly lower for the population surveys $(1.24,95 \%$ CI $1.17-1.31)$. The mortality and morbidity studies gave similar estimations for the CRR. Similarly, the CRR values did not differ according to the type of relative risks, except for the MOR values, which provided a lower CRR value $(1.21,95 \%$ CI 0.99-1.48). The CRR values for the welding subgroups were similar (1.32 for shipyard and mild steel welders and 1.31 for stainless steel welders). The CRR was smaller (1.24) for the nonspecific welding category. No heterogeneity was detected according to study design, types of relative risk, and welding category.

Countries and years of publication were also tested as to whether they could be sources of heterogeneity. The results were lower when the studies published in North America were considered versus those published in northern Europe or in other countries [CRR 1.22 (95\% CI 1.13-1.32) using random and fixed effects for North America, CRR 1.27 (95\% CI 1.20-1.35) for north European studies and CRR 1.30 (95\% CI 1.14-1.49) for all other countries]. Three periods were defined for the years of publication, each of them including approximately one-third of the relative risks. The CRR values using fixed or random effects did not differ [CRR 1.09 (95\% CI 0.96-1.24) for 1954-1985, 1.34 (95\% CI 1.211.48) for 1986-1993, and 1.27 (95\% CI 1.20 - 1.34) for 1994-2004]. No trend according to years of publication was thus detected, but the CRR of the first period was significantly lower than the overall CRR.

Among the 13 studies that had no reporting bias and provided tobacco adjusted relative risks, 11 reported relative risks higher than unity $(22,25,26,35,58,61-62$, $66,68-70)$. When crude and adjusted relative risks were available, it appeared that no or only slight confounding due to smoking was detected (25-26, 61, 69-70). The results were similar for the cohort studies that used Axelson's method $(34,37,79-80,82,87)$. The CRR values were higher for the studies with adjustment for tobacco smoking $(1.29,95 \%$ CI 1.17-1.43) than for those without adjustment (1.24, 95\% CI 1.17-1.30), the finding indicating that the lung cancer excesses could not be only due to smoking.

\section{Discussion}

The aim of our present meta-analysis was to improve our previous one (2) by including a greater number of studies and improving the methods used to address between-study heterogeneity and publication bias. We thus included 24 studies providing 28 relative risks that had not been included earlier. This rather large number is

Table 3. Meta-analysis considering potential sources of heterogeneity (only for studies without any indication on result reporting (ie, "unbiased results").(CRR = combined relative risks, $95 \% \mathrm{CI}=95 \%$ confidence interval, IOR = incidence odds ratio, SIR = standardized incidence ratio, $\mathrm{MOR}=$ mortality odds ratio, $\mathrm{SMR}=$ stamdardized mortality ratio)

\begin{tabular}{|c|c|c|c|c|c|c|c|}
\hline & \multirow{2}{*}{$\begin{array}{c}\text { Number } \\
\text { of } \\
\text { relative risks }\end{array}$} & \multicolumn{2}{|c|}{ Fixed effects } & \multicolumn{2}{|c|}{ Random effects } & \multirow[t]{2}{*}{ Q statistic } & \multirow[t]{2}{*}{ P-value } \\
\hline & & CRR & $95 \% \mathrm{Cl}$ & CRR & $95 \% \mathrm{Cl}$ & & \\
\hline Population surveys & 7 & 1.24 & $1.17-1.31$ & 1.23 & $1.15-1.32$ & 6.9 & 0.33 \\
\hline Case-control studies & 16 & 1.27 & $1.11-1.46$ & 1.27 & $1.11-1.46$ & 13.0 & 0.60 \\
\hline Cohort studies & 38 & 1.29 & $1.19-1.40$ & 1.29 & $1.19-1.40$ & 20.6 & 0.99 \\
\hline \multicolumn{8}{|l|}{ Exposure } \\
\hline Unspecified & 26 & 1.24 & $1.18-1.31$ & 1.24 & $1.18-1.31$ & 18.4 & 0.82 \\
\hline Shipyards & 16 & 1.32 & $1.16-1.51$ & 1.32 & $1.16-1.51$ & 14.3 & 0.50 \\
\hline Mild steel & 8 & 1.32 & $1.10-1.59$ & 1.32 & $1.10-1.59$ & 3.51 & 0.83 \\
\hline Stainless steel & 11 & 1.31 & $1.06-1.61$ & 1.31 & $1.06-1.61$ & 3.83 & 0.95 \\
\hline Morbidity studies & 22 & 1.26 & $1.19-1.34$ & 1.26 & $1.19-1.34$ & 15.4 & 0.80 \\
\hline Mortality studies a & 35 & 1.25 & $1.14-1.37$ & 1.25 & $1.14-1.37$ & 24.1 & 0.90 \\
\hline IOR & 13 & 1.28 & $1.11-1.47$ & 1.28 & $1.11-1.47$ & 10.3 & 0.59 \\
\hline SIR & 9 & 1.26 & $1.18-1.34$ & 1.26 & $1.18-1.34$ & 5.0 & 0.75 \\
\hline MOR & 10 & 1.21 & $0.99-1.48$ & 1.21 & $0.98-1.49$ & 9.5 & 0.39 \\
\hline SMR & 22 & 1.26 & $1.11-1.43$ & 1.26 & $1.11-1.43$ & 14.4 & 0.85 \\
\hline Other & 7 & 1.26 & $1.15-1.38$ & 1.26 & $1.15-1.38$ & 1.9 & 0.93 \\
\hline
\end{tabular}

a Except studies providing proportional mortality ratio. 
due to the fact that, after the IARC multicentric study published at the beginning of the 1990s (30-31), efforts have been made in industrialized countries to set up several epidemiologic studies specifically aimed at assessing lung cancer risks of stainless steel versus mild steel welders and at improving methods for taking smoking into account.

Our present meta-analysis failed to detect substantial heterogeneity since the CRR values were similar according to the different potential sources of heterogeneity. A possible exception was the low CRR for the studies published before 1984. This low figure was primarily due to three population surveys in the United States (40, 42, 45), whose relative risk estimates were lower than one and based on MOR and PMR values.

The results of a meta-analysis may be biased if the probability of publishing a study is influenced by the results $(3,6,89)$. In particular, finding increased risks may increase the chances of publication and thus result in an overestimation of CRR values. A publication bias was detected in this meta-analysis using a funnel plot and Egger regression. Our strategy to control for this publication bias consisted in excluding studies identified as having a positive reporting bias. Despite the loss of power due to study exclusion, and even if this method probably underestimates publication bias, we considered that this approach led to a better effect estimate. This strategy seemed effective, as no publication bias, as assessed by Egger's regression, was detected after the exclusion of B-coded studies.

According to our present meta-analysis, the estimate of lung cancer risk among welders, as compared with nonwelders, was 1.26. Another main outcome was that the CRR values were similar for mild steel and stainless steel welders. These results do not support the hypothesis that stainless steel welders are at higher lung cancer risk than mild steel welders, despite their probable exposure to chromium and nickel compounds in welding fumes. This finding agrees with the results of our previous meta-analysis (2), as well as with the conclusions of the large multicentric European study (30$31)$ and with the IARC monograph on lung cancer among welders (1).

A few studies, mostly industrial cohorts, investigated the existence of a dose-response relationship, but most of them used different dose surrogates. It was therefore impossible to compute dose-related CRR values. The multicentric European study included a large cohort of 11092 welders from nine European countries (30-31). The cohort was followed for mortality and cancer incidence. An ad hoc job-exposure matrix was developed to assess exposure to chromium (metal, trivalent, hexavalent) and nickel (90). This study failed to detect any dose-response relationship between lung cancer occurrence and cumulative exposure to hexavalent chromium or nickel (31). In 14 other studies, employment duration as a welder was used as a quantitative exposure estimate, but the time periods used differed between the studies. In six papers, the results for the welders with $>20$ years of exposure were available (18, $24,26,33,37,66)$. Four of them showed an SMR above one, but none of them reached significance. Van Loon et al (67) built a "cumulative probability of exposure" that combines the probability of exposure and exposure duration in three categories. They found a statistically significant dose-response relationship (trend $\mathrm{P}=0.03$ ), but this trend disappeared after adjustment for smoking and other occupational exposures. Gustavsson et al (69), applying a job-exposure matrix, calculated a cumulative dose but failed to demonstrate any relationship, as did Jöckel et al (25) using an index based on an estimation of the lifetime number of welding hours. In fact, only three studies reported a significant dose-response relationship. Two of them $(36,80)$ were conducted among shipyard welders and suggested a possible confounding by asbestos exposure.

On the whole, despite some positive results, the data are too limited to reach a conclusion about a dose-response relationship between welding and lung cancer risk.

Another outcome of our present meta-analysis is that shipyard welders have lung cancer CRR values that are similar to those of other welders (table 3 ). This observation confirms the previous result of the IARC study (31). However, this result is surprising, as several authors considered asbestos exposure to be more likely to have occurred in shipyards than in factories $(2,91,92)$. This conclusion raises the question of the extent to which asbestos exposure among welders could explain the lung cancer excesses. The use of asbestos protection devices (blanket, aprons, gloves, etc) was common among welders, so that welding is considered an occupation for which asbestos exposure is likely to have occurred $(31,91,92)$. This assumption is confirmed by the fact that significant excesses of mesothelioma have been reported for several cohorts of welders $(21,22,31,35$, 51, 75, 82, 91, 92). However, some case-control studies have reported that asbestos-adjusted odds ratios remained elevated $(10,23,25,67)$.

In our present meta-analysis, it was impossible to evaluate the part played by exposure to asbestos with respect to lung cancer excess, as the information available from the reviewed epidemiologic studies was too poor to be used in the calculation of the CRR values.

Smoking is a major risk factor to be considered in epidemiologic studies focused on lung cancer risk. Some population surveys in the United States have suggested that welders may smoke more than the general male population (93-95), so that smoking could act as a confounder. Unfortunately, the information on smoking is 
very often lacking in the selected studies. The only direct evidence against a strong role of smoking comes from the case-control studies, which did not find substantial changes in the relative risks after adjustment. The adjusted CRR values seemed to confirm this observation. A residual confounding can however not be ruled out.

In conclusion, our meta-analysis showed a $26 \%$ excess of lung cancer for welders and little heterogeneity between the studies once the positive reporting bias was accounted for. No difference between mild steel and stainless steel welders could be shown. This risk cannot be explained by confounding by smoking. The precise role of asbestos could however not be assessed.

\section{References}

1. International Agency for Research on Cancer (IARC). Chromium, nickel and welding fumes. Lyon: IARC, 1990. IARC monographs on the evaluation of carcinogenic risks to humans, vol 49.

2. Moulin JJ. A meta-analysis of epidemiologic studies of lung cancer in welders. Scand J Work Environ health. 1997; 23(2):104-13.

3. Greenland S. Meta-analysis. In: Rothman KJ, Greenland S. Modern epidemiology $2 \mathrm{~d}$ edition. Philadelphia (): Lippicottraven; 1998.

4. Hardy RJ, Thomson SG. Detecting and describing heterogeneity in meta-analysis. Stat Med. 1998;17:841-56.

5. Higgins JPT, Thomson SG. Quantifying heterogeneity in a meta-analysis. Stat Med. 2002;21:1-20.

6. Egger M, Smith GD, Schneider M, Minder C. Bias in metaanalysis detected by a simple, graphical test. BMJ. 1997;315:629-34.

7. Milham S. Cancer mortality patterns associated with exposure to metals. Ann N Y Acad Sci. 1976;271:243-9.

8. Sjögren B, Malker H. Chromium and asbestos as two probable risk factors in lung cancer among welders. J Occup Med. 1982;24:874-5.

9. Milham SJ. Occupational mortality in Washington State 19501974. Cincinnati (OH): US Department Health and Human Services; 1983. NIOSH Publ 83-116.

10. Jöckel KH, Ahrens W, Bolm-Audorff U. Lung cancer risk and welding. Preliminary results from an ongoing case-control study. Am J Ind Med. 1994;25:805-12.

11. Puntoni R, Vercelli M, Merlo F, Valerio F, Santi L. Mortality among shipyard workers in Genoa, Italy. Ann N Y Acad Sci. 1979;330:353-77.

12. Beaumont BJ, Weiss NS. Mortality of welders, shipfitters, and other metal trades workers in boilermakers local no 104, AFLCIO. Am J Epidemiol. 1980;112:775-86.

13. Sjögren B. A retrospective cohort study of mortality among stainless steel welders. Scand J Work Environ Health. 1980; 6:197-200

14. Becker N, Claude J, Frentzel-Beyme R. Cancer risk of arc welders exposed to fumes containing chromium and nickel. Scand J Work Environ Health. 1985;11:75-82.

15. Puntoni R, Vercelli M, Di Giorgio F, Valerio F, Bonassi S, Ceppi M, et al. Mortality study among autogenous and electri- cal welders in the port of Genoa (Italy). In: Stern RM, Berlin A, Fletcher AC, Järvisalo J, editors. Proceedings of the international conference on health hazards and biological effects of welding fumes and gases; February 1985, Amsterdam: Excerpta Med. 1986;469-72.

16. Sjögren B, Gustavsson A, Hedström L. Mortality in two cohorts of welders exposed to high- and low-levels of hexavalent chromium. Scand J Work Environ Health. 1987;13:24751.

17. Melkild A, Langård S, Andersen A, Stray Tønnessen JN. Incidence of cancer among welders and other workers in a Norwegian shipyard. Scand J Work Environ Health. 1989; 15:387-94.

18. Steenland K, Beaumont J, Eliot L. Lung cancer in mild steel welders. Am J Epidemiol. 1991;133:220-9.

19. Becker N, Chang-Claude J, Frentzel-Beyme R. Risk of cancer for arc welders in the Federal Republic of Germany: results of a second follow up (1983-8). Br J Ind Med. 1991;48:675-83.

20. Hansen K S, Lauritsen J. A nested case-control study of lung cancer in welders and other metal workers. In: Proceedings of the 9th International Symposium in Epidemiology in Occupational Health; 23-25 September 1992, Cincinnati, Ohio. Cincinnati (OH): US Department of Health and Human Services, Public Health Service; 1994. NIOSH publication, no 94112.

21. Sjögren B, Weiner J, Horte LG, Carstensen J. Mortality among Swedish welders and gas-cutters. In: Stern RM, Berlin A, Fletcher AC, Järvisalo J, editors. Proceedings of the international conference on health hazards and biological effects of welding fumes and gases; February 1985, Amsterdam: Excerpta Med. 1986;457-9.

22. Sjögren B, Carstensen J. Cancer morbidity among Swedish welders and gas cutters. In: Stern RM, Berlin A, Fletcher AC, Järvisalo J, editors. Proceedings of the international conference on health hazards and biological effects of welding fumes and gases; February 1985, Amsterdam: Excerpta Med 1986;461-3.

23. Jöckel KH, Ahrens W, Jahn I, Pohlabeln H, Ulrich BA. Occupational risk factors for lung cancer: a case-control study in West Germany. Int J Epidemiol. 1998;27:549-60.

24. Hansen KS, Lauritsen JM, Skytthe A. Cancer incidence among mild steel and stainless steel welders and other metal workers. Am J Ind Med. 1996;30:373-82.

25. Jöckel KH, Ahrens W, Pohlabeln H, Ulrich BA, Klaus MM. Lung cancer risk and welding: results from a case-control study in Germany. Am J Ind Med. 1998;33:313-20.

26. Lauritsen JM, Hansen KS. Lung cancer mortality in Stainless and mild steel welders: a nested case-referent study. Am J Ind Med. 1996;30:383-91.

27. Håkansson N, Floderus B, Gustavsson P, Johansen C, Olsen $\mathrm{JH}$. Cancer incidence and magnetic field exposure in industries using resistance welding in Sweden. Occup Environ Med. 2002;59:481-6.

28. Verma DK, Julian JA, Roberts RS, Muir DCF, Jadon N, Shaw DS. Polycyclic aromatic hydrocarbons (PAHs): a possible cause of lung cancer mortality among nickel/copper smelter and refinery workers. Am Ind Hyg Assoc J. 1992;53(5):31724.

29. Keller JE, Howe HL. Cancer in Illinois construction workers: a study. Am J Ind Med. 1993;24:223-30.

30. Simonato L, Winkelman R, Ferro G, Saracci R, Charnay N. Mortality and cancer incidence follow up of an historical cohort of European welders. Lyon: International Agency for Research on Cancer; 1989. IARC International Report 89 / 
003.

31. Simonato L, Fletcher AC, Andersen A, Anderson K, Becker $\mathrm{N}$, Chang-Claude J, et al. An historical prospective study of European stainless steel, mild steel and shipyard welders. Br J Ind Med. 1991;48:145-54.

32. Tola S, Kalliomäki PL, Pukkala E, Asp S, Korkala ML. Incidence of cancer among welders, platters, machinists, and pipe fitters in shipyards and machine shops. Br J Ind Med. 1988;45:209-18.

33. Moulin JJ, Wild P, Haguenoer JM, Faucon D, de Gaudemaris R, Mur JM, et al A mortality study among mild steel and stainless steel welders. Br J Ind Med. 1993;50:234-43.

34. Milatou-Smith R, Gustavsson A, Sjögren B. Mortality among welders exposed to high and to low levels of hexavalent chromium and followed for more than 20 years. Int J Occup Environ Health. 1997;3:128-31.

35. Becker N. Cancer mortality among arc welders exposed to fumes containing chromium and nickel. J Occup Environ Med. 1999;41:294-303.

36. Beaumont JJ, Weiss NS. Lung cancer among welders. J Occup Med. 1981;23:839-44.

37. Steenland K. Ten-year update on mortality among mild-steel welders. Scand J Work Environ Health. 2002;28(3):163-7.

38. Axelson O, Steenland K. Indirect methods of assessing the effects of tobacco use in occupational studies. Am J Ind Med. 1988;13:105-18.

39. Spinelli JJ, Band PR, Gallagher RP. Adjustment for confounding in occupational cancer epidemiology. Recent Results Cancer Res. 1990;120:64-77.

40. Enterline PE, McKiever M. Differential mortality from lung cancer by occupation. J Occup Med. 1963;5:283-90.

41. Menck HR, Henderson BE. Occupational differences in rates of lung cancer. J Occup Med. 1976;18:797-801.

42. Decoufle P, Stanislawczyk K, Houten L, Bross J, Viadana E. Retrospective survey of cancer in relation to occupation. Cincinnati $(\mathrm{OH})$ : National Institute for Occupational Safety and Health (NIOSH); 1978. NIOSH publication, no 77-178.

43. Office of Population Censuses and Surveys. Occupational mortality, 1970-1972: England and Wales: decennial supplement. London: Her Majesty's Stationary Office; 1978.

44. Gottlieb MS. Lung cancer and the petroleum industry in Louisiana. J Occup Med. 1980;22:384-8.

45. Peterson GR, Milham JS. Occupational mortality in the state of California 1969-1971. Cincinnati (OH): National Institute for Occupational Safety and Health; 1980. NIOSH publication, no 80-104.

46. Milne K, Sandler DP, Everson RB, Brown SM. Lung cancer and occupation in Alameda county: a death certificate casecontrol study. Am J Ind Med. 1983;4:565-75.

47. Gallagher RP. Cancer mortality in metal workers. Can Med Assoc J. 1983;129:1191-4.

48. Firth HM, Herbison GP, Cooke KR, Fraser J. Male cancer mortality by occupation. N Z Med J. 1993;106:328-30.

49. Milham SJ. Occupational mortality in Washington State 19501989. Cincinnati (O): US Department Health and Human Services; 1997. NIOSH publication, no 00913725.

50. Burnett C, Maurer J Dosemeci M. Mortality by occupation, industry, and cause of death, 24 reporting States (19841988). Cincinnati (OH): US Department Health and Human Services; 1997. NIOSH publication, no 97-114.

51. Andersen A, Barlow L, Engeland A, Kjærheim K, Lynge E, Pukkala E. Work related cancer in the Nordic countries. Scand J Work Environ Health. 1999;25 suppl 2:54-6.

52. Breslow L, Hoaglin L, Rasmussen G, Abrams HK. Occupa- tions and cigarette smoking as factor in lung cancer. Am J Public Health. 1954;44:171-81.

53. Blot WJ, Harrington JM, Toledo A, Hoover R, Heath CW, Fraumeni JF. Lung cancer after employment in shipyards during World War II. N Engl J Med. 1978;299:620-4.

54. Blot WJ, Morris L E, Stroube R, Tagnon I, Fraumeni J F. Lung and laryngeal cancers in relation to shipyard employment in Coastal Virginia. J Natl Cancer Inst 1980;65:571-5.

55. Gérin M, Siemiatycki G, Richardson L, Pellerin J, Lakhani R, Dewar R. Nickel and cancer associations from a multicancer occupation exposure case-referent study: preliminary findings. In: Sunderman FW, editor. Nickel in the human environment. Lyon: International Agency for Research on Cancer (IARC); 1984. IARC Scientific publication, no 53, 105-15.

56. Buiatti E, Kriebel D, Geddes M, Santucci M, Pucci N. A case control study of lung cancer in Florence, Italy, I: occupational risk factors. J Epidemiol Community Health. 1985;39:24450.

57. Kjuus H, Skjærven R, Langård S, Lien JT, Aamodt T. A casereferent study of lung cancer, occupational exposures and smoking, I: comparison of title-based and exposure-based occupational information. Scand J Work Environ Health. 1986;12:193-202.

58. Schoenberg JB, Stemhagen A, Mason TJ, Patterson J, Bill J, Altman R. Occupation and lung cancer risk among New Jersey white males. J Natl Cancer Inst. 1987;79:13-21.

59. Lerchen ML, Wiggins CL, Samet JM. Lung cancer and occupation in New Mexico. J Natl Cancer Inst. 1987;79:639-45.

60. Benhamou S, Benhamou E, Flamant R. Occupational risk factors of lung cancer in a French case-control study. Br J Ind Med. 1988;45:231-3.

61. Ronco G, Ciccione G, Mirabelli D, Troia B, Vineis P. Occupation and lung cancer in two industrialized areas of northern Italy. Int J Cancer. 1988;41:354-8.

62. Zahm SH, Brownson RC, Chang JC, Davis JR. Study of lung cancer histologic types, occupation, and smoking in Missouri. Am J Ind Med. 1989;15:565-78.

63. Hull CJ, Doyle E, Peters JM, Garabrant DH, Bernstein L, Preston-Martin S. Case-control study of lung cancer in Los Angeles county welders. Am J Ind Med. 1989;16:103-12.

64. Morabia A, Markowitz S, Garibaldi K, Wynder EL. Lung cancer and occupation: results of a multicentre case-control study. Br J Ind Med. 1992;49:721-7.

65. Finkelstein MM. Occupational associations with lung cancer in two Ontario cities. Am J Ind Med. 1995;27:127-36.

66. De Stefani E, Kogevinas M, Boffetta P, Ronco A, Mendilaharsu M. Occupation and the risk of lung cancer in Uruguay. Scand J Work Environ Health. 1996;22:346-52.

67. Van Loon MJM. Occupational exposure to carcinogens and risk of lung cancer: results from The Netherlands cohort study. Occup Environ Med. 1997;54:817-24.

68. Pezzoto SM, Poletto L. Occupation and histopathology of lung cancer: a case-control study in Rosario, Argentina. Am J Ind Med. 1999;36:437-43.

69. Gustavsson P, Jakobsson R, Nyberg F, Pershagen G, Järup L, Schéele P. Occupational exposure and lung cancer risk: a population-based case-referent study in Sweden. Am J Epidemiol. 2000;152:32-40.

70. Matos EL, Vilensky M, Mirabelli D, Boffeta P. Occupational exposures and lung cancer in Buenos Aires, Argentina. J Occup Environ Med. 2000;42:653-9.

71. Dunn JE, Weir JM. A prospective study of mortality of several occupational groups: special emphasis on lung cancer. Arch Environ Health. 1968;17:71-6. 
72. Ott MG, Holder BB, Langner RR. Determinants of mortality in an industrial population. J Occup Med. 1976;18: 171-7.

73. Redmond CK, Wieand HS, Rockette HE, Sass R, Weinberg G. Long term mortality experience of steel workers. Cincinnati (OH): US Department Health and Human Services; 1981, NIOSH publication, no 81120.

74. Polednak AP. Mortality among welders, including a group exposed to nickel oxides. Arch Environ Health. 1981;36:23542.

75. McMillan GHG, Pethybridge RJ. The health of welders in Naval Dockyards: proportional mortality study of welders and two control groups. J Soc Occup Med. 1983;33:75-84.

76. Fletcher AC, Ades A. Lung cancer mortality in a cohort of English foundry workers. Scand J Work Environ Health. 1984;10:7-16.

77. Newhouse ML, Oakes D, Woolley AJ. Mortality of welders and other craftsmen at a shipyard in NE England. Br J Ind Med. 1985;42:406-10.

78. Rinsky RA, Melius JM, Hornung RW, Zumwalde RD, Waxweiler RJ, Landrigan J, et al. Case-control study of lung cancer in civilian employees at the Portsmouth naval shipyard, Kittery, Maine. Am J Epidemiol. 1988;127:55-64.

79. Merlo F, Costantini M, Doria M. Cause specific mortality among workers exposed to welding fumes and gases: a historical prospective study. In: International Conference on Industrial Health and the VIIIth UOEH International SymposiumHealth. J UOEH. 1989;suppl 11:302-15.

80. Danielsen E, Langård S, Andersen A, Knudsen Ø. Incidence of cancer among welders of mild steel and other shipyard workers. Br J Ind Med. 1993;50:1097-103.

81. Park R, Krebs J, Mirer F. Mortality at an automotive stamping and assembly complex. Am J Ind Med. 1994;26: 449-63.

82. Danielsen TK, Langård S, Andersen A. Incidence of cancer among Norwegian boiler welders. Occup Environ Med. 1996;53:231-4.

83. Austin H, Delzell E, Lally C, Rotimi C, Oestenstad K. A casecontrol study of lung cancer at a foundry and two engine plants. Am J Ind Med. 1997;31:414-21.

84. Stern FB, Sweeney MH, Ward E. Proportionate mortality among unionized construction Ironworkers. Am J Ind Med. 1997;31:176-87.

85. Danielsen TE, Langård S, Andersen A. Incidence of lung cancer among shipyard welders investigated for Siderosis. Int J Occup Environ Health. 1998;4:85-8.

86. de Silva RS, Bundy ED, Smith PD, Gaydos JC. A geographical information system technique for record matching in a study of cancer deaths in Welders. J Occup Environ Med. 1999;41:464-8.

87. Danielsen TE, Langård S, Andersen A. Incidence of cancer among welders and other shipyard workers with information on previous work history. J Occup Environ Med. 2000;42:101-8.

88. Puntoni R, Merlo F, Borsa L, Reggiardo G, Garrone E, Ceppi M. A historical cohort mortality study among shipyard workers in Genoa, Italy. Am J Ind Med. 2001;40:363-70.

89. Begg CB, Mazumdar M. Operating characteristics of a rank correlation test for publication bias. Biometrics. 1994;50:1088-101.

90. Gerin M, Fletcher AC, Gray C, Winkelman R, Boffetta P, Simonato L. Development and use of a welding process exposure matrix in a historical prospective study of lung cancer risk in European welders. Int J Epidemiol. 1993;22 suppl 2:S22-S27.

91. Sheers G, Coles RM. Mesothelioma risks in a Naval Dockyard. Arch Environ Health. 1980;35:276-82.

92. McMillan GHG. The health welders in naval dockyard: the risk of asbestos-related diseases occurring in welders. J Occup Med. 1983;10:727-30.

93. Sterling TD, Weinkam JJ. Smoking characteristics by type of employment. J Occup Med. 1976;18: 743-54.

94. Brackbill R, Frazier T, Shilling S. Smoking characteristics of US workers, 1978-1980. Am J Ind Med. 1988;13:5-41.

95. Nelson D E, Emont S L, Brackbill R, Lorraine L, Peddicord J, Fiore MC. Cigarette smoking prevalence by occupation in the United States: a comparison between 1978 to 1980 and 1987 to 1990. J Occup Med. 1994;36:516-25.

Received for publication: 23 June 2005 